\title{
Mortality Associated with Dose Response of Erythropoiesis-Stimulating Agents in Hemodialysis versus Peritoneal Dialysis Patients
}

\author{
Uyen Duong ${ }^{\mathrm{a}}$ Kamyar Kalantar-Zadeh ${ }^{\mathrm{a}-\mathrm{d}}$ Miklos Z. Molnar ${ }^{\mathrm{a}} \mathrm{h}$ \\ Joshua J. Zaritsky ${ }^{c}$ Isaac Teitelbaum ${ }^{\mathrm{e}}$ Csaba P. Kovesdy ${ }^{f, g}$ Rajnish Mehrotrab, c \\ a Harold Simmons Center for Chronic Disease Research and Epidemiology, Los Angeles Biomedical Research \\ Institute at Harbor-UCLA Medical Center, and bivision of Nephrology and Hypertension, Harbor-UCLA Medical \\ Center, Torrance, Calif., 'David Geffen School of Medicine at UCLA, and ${ }^{\mathrm{d}}$ Department of Epidemiology, UCLA \\ School of Public Health, Los Angeles, Calif., e University of Colorado, Denver, Colo., fDivision of Nephrology, \\ Salem VA Medical Center, Salem, Va., and ${ }^{9}$ Division of Nephrology, University of Virginia, Charlottesville, Va., USA; \\ hInstitute of Pathophysiology, Semmelweis University, Budapest, Hungary
}

\section{Key Words}

Anemia $\cdot$ Hemoglobin $\cdot$ Erythropoietin-stimulating agent therapy • Peritoneal dialysis · Hemodialysis • Mortality • Cardiovascular mortality

\begin{abstract}
Background: Several studies have shown an association between erythropoietin-stimulating agent (ESA) responsiveness and mortality in chronic kidney disease (CKD) patients. In our present study, we examined the association between prescribed ESA dose and mortality in peritoneal dialysis (PD) and hemodialysis (HD) patients. We hypothesized that PD patients received lower ESA dose for the same achieved hemoglobin compared to HD patients and that ESA dose-mortality associations were different between PD and HD patients. Methods: We compared the prescribed doses of ESA between 139,103 HD and 10,527 PD patients treated in DaVita dialysis clinics from 7/2001 through 6/2006 using adjusted Poisson regression and examined mortality-predictability of prescribed ESA dose and ESA responsiveness index (ESA/hemoglobin) in PD and HD with follow-up through
\end{abstract}

6/2007 using Cox regression models. Results: Poisson adjusted ratio of ESA dose of HD to PD was 3.6 (95\% Cl 3.5-3.7). In PD patients, adjusted all-cause death hazard ratios (HR) for ESA doses of 3,000-5,999, 6,000-8,999 and $\geq 9,000 \mathrm{U} /$ week (reference $<3,000 \mathrm{U} /$ week) were 0.97 (0.87-1.07), 0.85 (0.76$0.95)$ and 1.08 (0.98-1.18), respectively; whereas in HD patients across commensurate ESA dose increments of 10,00019,999, 20,000-29,999 and $\geq 30,000 \mathrm{U} /$ week (reference $<10,000 \mathrm{U} /$ week) were 1.14 (1.11-1.17), 1.54 (1.50-1.58) and 2.15 (2.10-2.21), respectively. In PD and HD patients, the adjusted death HR of the 4th to 1st quartile of ESA responsiveness index were 1.14 (1.04-1.26) and 2.37 (2.31-2.43), respectively. Conclusions: Between 2001 and 2006, most PD patients received substantially lower ESA dose for same achieved hemoglobin levels, and low ESA responsiveness was associated with higher mortality in both HD and PD patients.

Copyright $\odot 2012$ S. Karger AG, Basel

\section{KARGER}

Fax +4161306 1234 E-Mail karger@karger.ch www.karger.com
(C) 2012 S. Karger AG, Basel

0250-8095/12/0352-0198\$38.00/0

Accessible online at:

www.karger.com/ajn
Kamyar Kalantar-Zadeh, MD, PhD, MPH
Harold Simmons Center for Chronic Disease
Division of Nephrology and Hypertension, Harbor-UCLA Medical Center
1124 West Carson Street, C1-Annex, Torrance, CA 90509-2910 (USA)

Tel. +1 310222 3891, E-Mail kamkal@ ucla.edu 


\section{Introduction}

Anemia is present in most patients with chronic kidney disease (CKD) treated with maintenance hemodialysis (HD) or peritoneal dialysis (PD) [1-3]. Observational studies have repeatedly found anemia and hemoglobin variability to associate with adverse clinical outcomes in patients with various degrees of CKD $[2,4$, 5]. Recent prospective randomized trials testing the effect of erythropoietin-stimulating agents (ESAs) in CKD patients [6-10], however, have suggested that targeting hemoglobin to normal or near-normal levels in CKD does not confer a survival benefit, nor any substantial improvement in health-related quality of life compared to delay in starting ESA when the hemoglobin level declines to $<9 \mathrm{~g} / \mathrm{dl}$ [7]. Prior to 2007, the administered ESA doses for US dialysis patients were higher than is currently the case $[11,12]$. During this period, the average ESA doses ranged from 17,832 U/week (nonprofit facilities with a mean hematocrit level of $34.6 \%$ ) to 24,986 $\mathrm{U} /$ week (for-profit facilities with a mean hematocrit level of 36.5\%) [11].

Several studies have shown an association between ESA responsiveness and mortality in CKD patients [13, 14]. A recent secondary analysis of the Trial to Reduce Cardiovascular Events with Aranesp therapy (TREAT) showed that a poor initial response to ESA therapy was associated with increased cardiovascular and all-cause mortality [15]. It has been suggested that the received dose of ESA to achieve certain hemoglobin level, also known as the ESA hyporesponsiveness index, has a bearing on ESA survival associations [16]. In addition to the CKD population not yet on dialysis, poor response to ESA therapy is associated with increased mortality in HD patients as well [17]. It is possible, although never tested in randomized trials, that ESA itself, rather than targeted hemoglobin concentration, mediates the increased risk of adverse vascular outcomes [18]. The Clinical Evaluation of the Dose of Erythropoietins (CE-DOSE) trial is expected to more accurately assess the benefits and harms of a high versus a low fixed ESA dose for the management of anemia in patients with end-stage renal disease [19]. However, to our knowledge no study has examined the association between ESA hyporesponsiveness and mortality in PD patients, or compared it to that in $\mathrm{HD}$ patients.

Recent data from the UK Renal Registry showed that the prescribed ESA dose in HD patients was $100 \%$ higher prescribed than in PD patients [20]; this observation was confirmed by Coronel et al. [21]. In CKD patients, the ESA hyporesponsiveness may be related to chronic inflammation, iron deficiency and hyperparathyroidism, among other conditions [22-26]. The prevalence and predictors of these factors might be different between PD and HD patients, which may be reflected by the differences in received prescribed ESA dose between these two dialysis modalities [27]. We are not aware of any prior study in large cohorts of dialysis patients to compare ESA dose and responsiveness in PD and HD populations. Using a large and contemporary cohort of all dialysis patients from a single dialysis provider in the United States between mid-2001 and mid-2006 with extensive clinical and laboratory data, we examined the hypothesis that PD patients receive lower ESA doses for the same achieved hemoglobin compared to HD patients and that higher ESA dose is associated with increased risk of mortality in both PD and HD population.

\section{Methods}

Patients

We extracted, refined and examined data from all individuals with ESRD who underwent PD or HD treatment from July 2001 through June 2006 in any one of the 580 outpatient dialysis facilities of DaVita, a large dialysis organization in the US (prior to its acquisition of clinics owned by Gambro). The study was approved by relevant Institutional Review Committees. The 5-year (7/2001-6/2006) national database of all DaVita dialysis patients included 164,789 cumulative subjects; of these, 13,312 were excluded for lack of data regarding baseline dialysis modality. Of the remaining 151,477 patients, 10,527 were treated with PD and 139,103 were treated with HD and the modality was uncertain in 1,847 patients. Inclusion criteria for the study were patients who had been undergoing dialysis for at least 90 days and were treated with PD or $\mathrm{HD}$ at the time of entry into the cohort.

\section{Clinical and Demographic Measures}

The creation of the cohort has been described previously [2835]. To minimize measurement variability, all repeated measures for each patient during any given calendar quarter, i.e. over a 13week interval, were averaged and the summary estimate was used in all models. Average values were obtained from up to 20 calendar quarters ( $\mathrm{q} 1$ through q20) for each laboratory and clinical measure for each patient for up to 6 years of follow-up. The first (baseline) studied quarter for each patient was the calendar quarter in which the patient's dialysis vintage was $>90$ days. The presence or absence of diabetes at baseline was obtained from DaVita data and verified in the United Stated Renal Data System (USRDS). Histories of tobacco smoking and preexisting co-morbid conditions were obtained by linking the DaVita database to the Medical Evidence Form 2728 of the USRDS and categorized into $10 \mathrm{co}-$ morbid conditions: ischemic heart disease, congestive heart failure, history of cardiac arrest, history of myocardial infarction, 
Table 1. Baseline data of 10,527 PD patients and 139,103 HD patients from a cohort of dialysis patients between 6/2001 and $7 / 2006$

\begin{tabular}{|c|c|c|c|}
\hline & $\begin{array}{l}\text { All PD } \\
\text { patients } \\
(10,527)\end{array}$ & $\begin{array}{l}\text { All HD } \\
\text { patients } \\
(139,103)\end{array}$ & $\mathrm{p}$ \\
\hline Age, years & $55 \pm 16$ & $62 \pm 16$ & $<0.001$ \\
\hline Female sex, $\%$ & 47 & 45 & $<0.001$ \\
\hline Diabetes, \% & 46 & 44 & $<0.001$ \\
\hline Race/ethnicity, \% & & & $<0.001$ \\
\hline Caucasian & 54 & 44 & \\
\hline Black & 21 & 32 & \\
\hline Hispanic & 14 & 14 & \\
\hline Other & 11 & 10 & \\
\hline Vintage (time on dialysis), \% & & & $<0.001$ \\
\hline$<6$ months & 62 & 53 & \\
\hline $6-24$ months & 18 & 19 & \\
\hline $2-5$ years & 14 & 18 & \\
\hline$>5$ years & 6 & 10 & \\
\hline Primary insurance: Medicare, $\%$ & 58 & 68 & $<0.001$ \\
\hline $\mathrm{BMI}, \mathrm{kg} / \mathrm{m}^{2}$ & $27.0 \pm 8.1$ & $26.7 \pm 7.1$ & $<0.001$ \\
\hline Serum albumin, g/dl & $3.6 \pm 0.5$ & $3.7 \pm 0.5$ & $<0.001$ \\
\hline Creatinine, mg/dl & $8.4 \pm 3.9$ & $8.0 \pm 3.3$ & $<0.001$ \\
\hline Ferritin, ng/ml & $370 \pm 446$ & $520 \pm 501$ & $<0.001$ \\
\hline TIBC, $\mu \mathrm{g} / \mathrm{dl}$ & $240 \pm 51$ & $208 \pm 47$ & $<0.001$ \\
\hline Serum iron $(\mathrm{Fe}), \mu \mathrm{g} / \mathrm{dl}$ & $71 \pm 30$ & $57 \pm 25$ & $<0.001$ \\
\hline TSAT (iron saturation), $\%$ & $30 \pm 13$ & $28 \pm 11$ & $<0.001$ \\
\hline Bicarbonate, mg/dl & $25 \pm 3$ & $22 \pm 3$ & $<0.001$ \\
\hline Phosphorus, mg/dl & $5.3 \pm 1.4$ & $5.6 \pm 1.5$ & $<0.001$ \\
\hline Calcium, mg/dl & $9.2 \pm 0.8$ & $9.2 \pm 0.7$ & 0.12 \\
\hline Blood hemoglobin, $\mathrm{g} / \mathrm{dl}$ & $12.2 \pm 1.5$ & $12.0 \pm 1.4$ & $<0.001$ \\
\hline WBC count, $\times 10^{3} / \mu l$ & $7.6 \pm 2.7$ & $7.5 \pm 2.6$ & $<0.001$ \\
\hline \multicolumn{4}{|l|}{ Lymphocytes, } \\
\hline$\%$ of total WBC count & $20 \pm 8$ & $20 \pm 8$ & $<0.001$ \\
\hline Death, n (\%) & $4,152(39)$ & $70,823(51)$ & $<0.001$ \\
\hline Cardiovascular death, & & & $<0.001$ \\
\hline$\%$ of all cause & 50 & 53 & \\
\hline Infectious death, $\%$ of all cause & 22 & 18 & $<0.001$ \\
\hline Cohort time, day & $830 \pm 563$ & $813 \pm 609$ & 0.003 \\
\hline
\end{tabular}

Data are presented as mean \pm SD unless otherwise stated.

pericarditis, cardiac dysrhythmia, cerebrovascular events, peripheral vascular disease, chronic obstructive pulmonary disease, and cancer [36]. Patients were followed for outcomes through June 30,2007 . The recorded causes of death were obtained from the USRDS, and cardiovascular death was defined as death due to myocardial infarction, cardiac arrest, heart failure, cerebrovascular accident, and other cardiac causes.

\section{Laboratory Measures}

Blood samples were drawn using uniform techniques in all dialysis clinics and were transported to the DaVita Laboratory in Deland, Fla., USA, usually within $24 \mathrm{~h}$. All laboratory values were measured by automated and standardized methods. Most laboratory values were measured monthly. The 3-month-averaged weekly ESA dose was used in our analyses. To examine the relationship of ESA dose increments to mortality in dialysis patients, we divided $\mathrm{HD}$ patients into four a priori categories of weekly ESA doses of $<10,000,10,000-19,999,20,000-29,999$ and $\geq 30,000 \mathrm{U} /$ week, so that each group included approximately 20,000-40,000 HD patients. Since PD patients received on average one-third of the ESA dose given to HD patients, we divided PD patients into four different but commensurate weekly ESA dose categories of $<3,000,3,000-5,999,6,000-8,999$ and $\geq 9,000$ U/week, which resulted in 1,500 to $3,000 \mathrm{PD}$ patients in each ESA group. In sensitivity analyses, we also divided PD patients into the same four ESA groups as HD patients to assess the association of extremely high ESA dose and PD outcomes.

\section{Epidemiologic and Statistical Methods}

Data were summarized using proportions and means $( \pm S D)$. Categorical variables were analyzed with the $\chi^{2}$ test and continuous variables were compared using the t test or ANOVA as appropriate.

Poisson regression was used to calculate ratio of prescribed ESA dose (as a count variable) between HD and PD after adjustment for covariates. Four levels of adjustment were used as follows: (1) unadjusted or minimally adjusted models included modality categories and entry calendar quarter (q1 through q20); (2) hemoglobin-adjusted models that included all of the above plus blood hemoglobin; (3) case-mix-adjusted models, and (4) case-mix plus malnutrition-inflammation-complex syndrome (MICS)-adjusted models adjusting for below mentioned co-variables.

Survival analyses with Cox time-averaged regression were used to examine whether ESA dose predicted survival during up to 6 years of follow-up. All-cause mortality was the primary outcome measure and cardiovascular mortality as a secondary outcome measure. In the mortality analyses, the patients were followed until event (death) or censoring (transplantation, departure from DaVita facilities or end of follow-up period) whichever happened first. For each analysis, three models were examined: (1) unadjusted or minimally adjusted models included ESA dose categories and entry calendar quarter (q1 through q20); (2) case-mix-adjusted models that included all of the above plus age, gender, race/ethnicity (African-Americans and other self-categorized Blacks, Non-Hispanic Whites, Asians, Hispanics and others), ten pre-existing co-morbid conditions, history of tobacco smoking, categories of dialysis vintage ( $<6$ months, 6 months to 2 years, $2-5$ years and $\geq 5$ years), primary insurance (Medicare, Medicaid, private, and others), and marital status (married, single, divorced, widowed, and other or unknown), presence of diabetes, serum ferritin and iron saturation, and (3) case-mix plus malnutrition-inflammation-complex syndrome (MICS)-adjusted models included all of the covariates in the case-mix model as well as 9 surrogates of nutritional status and inflammation, including body mass index, and 8 laboratory surrogates with known association with clinical outcomes in hemodialysis patients [30] including serum levels of albumin, total iron-binding capacity, creatinine, phosphorus, calcium, bicarbonate, blood white blood cell count and lymphocyte percentage. 
Table 2. Number of patients and crude ratios (R) of the prescribed ESA dose (HD to PD patients) across 12 increments of achieved hemoglobin levels in 10,380 PD patients and 121,863 HD patients between 7/2001 and $6 / 2006$

\begin{tabular}{lccc}
\hline Hemoglobin & \multicolumn{2}{l}{ ALL $(\mathrm{n}=132,243)$} & \\
\cline { 2 - 4 } & PD, $\mathrm{n}(\%)$ & HD, n (\%) & crude ratios (R) \\
\hline$<9.0 \mathrm{~g} / \mathrm{dl}$ & $95(1)$ & $1,687(1)$ & 3.9 \\
9.0 to $<9.5 \mathrm{~g} / \mathrm{dl}$ & $108(1)$ & $1,541(1)$ & 3.7 \\
9.5 to $<10.0 \mathrm{~g} / \mathrm{dl}$ & $179(2)$ & $2,621(2)$ & 3.1 \\
10.0 to $<10.5 \mathrm{~g} / \mathrm{dl}$ & $324(3)$ & $4,189(3)$ & 3.3 \\
10.5 to $<11.0 \mathrm{~g} / \mathrm{dl}$ & $698(7)$ & $6,859(6)$ & 3.4 \\
11.0 to $<11.5 \mathrm{~g} / \mathrm{dl}$ & $1,369(13)$ & $12,907(11)$ & 3.1 \\
11.5 to $<12.0 \mathrm{~g} / \mathrm{dl}$ & $2,291(22)$ & $27,689(23)$ & 2.9 \\
12.0 to $<12.5 \mathrm{~g} / \mathrm{dl}$ & $2,313(22)$ & $35,144(29)$ & 3.1 \\
12.5 to $<13.0 \mathrm{~g} / \mathrm{dl}$ & $1,521(15)$ & $18,554(15)$ & 3.0 \\
13.0 to $<13.5 \mathrm{~g} / \mathrm{dl}$ & $767(7)$ & $6,759(6)$ & 3.0 \\
13.5 to $<14.0 \mathrm{~g} / \mathrm{dl}$ & $381(4)$ & $2,322(2)$ & 2.9 \\
$\geq 14 \mathrm{~g} / \mathrm{dl}$ & $334(3)$ & $1,591(1)$ & 2.9 \\
All $\mathrm{patients}$ & 10,380 & 121,863 & 3.1 \\
\hline
\end{tabular}

Missing covariate data $(<1 \%$ in all covariate) were imputed by the mean or median of the existing values as appropriate. For all analysis, two-sided $\mathrm{p}$ values are reported and results considered statistically significant if $\mathrm{p}<0.05$. All statistical analyses were carried out with the SAS, version 9.1 (SAS Institute, Inc., Cary, N.C., USA) and STATA version 11.1 (STATA Corporation, College Station, Tex., USA).

\section{Results}

Over the 5-year period (7/2001-6/2006), 164,789 adult subjects received dialysis treatment in clinics owned by DaVita, of whom 10,527 patients were undergoing PD and 139,103 $\mathrm{HD}$ at the time of entry into the cohort. There were 4,152 deaths (39\%) in the PD group and 70,823 deaths (51\%) in HD group. The median follow-up time was 685 days (interquartile range: 3261,208 days).

Table 1 shows baseline demographic, clinical, and laboratory characteristics of the total population divided by baseline dialysis modality. Individuals with PD patients were younger, were more likely to be White, and had shorter dialysis vintage but lower serum albumin level. Table 2 shows number of patients and crude ratios (R) of the prescribed ESA dose (HD compared to PD patients) across 12 increments $(<9.0, \geq 14.0$ and $0.5 \mathrm{~g} / \mathrm{dl}$ increments) of achieved hemoglobin levels during the 20012006 era. HD patients with same levels of hemoglobin received 3-4 times higher ESA doses than $\mathrm{PD}$ patients; however, the distribution of hemoglobin in PD and HD patients was the same.

To examine the relative ratio (RR) of ESA dose between HD and PD after controlling for potential confounders such as age and race, we employed Poisson regression models. Table 3 shows the multivariate adjusted RR of prescribed dose of ESA in HD versus PD patients in the entire 2001-2006 cohort and across 4 mutually exclusive race and gender categories. The ESA dose ratio in the unadjusted model was more than 3 times higher in HD compared to PD patients (RR 3.5, 95\% CI 3.4-3.6) and remained similar even after case-mix and MICS adjustment (RR 3.6, 95\% CI 3.5-3.7). African-American male and female HD patients received even higher doses than their PD counterparts, i.e. adjusted RR of ESA dose of 3.8 and 4.0, respectively, whereas among non-AfricanAmericans, the adjusted dose RR were 3.4 and 3.7, respectively. Table 4 shows the adjusted RR of prescribed dose of ESA in HD to PD patients across hemoglobin levels. HD patients with lower hemoglobin levels $(<11$ g/dl) received 4-5 times higher doses than PD patients, whereas across hemoglobin levels above $11 \mathrm{~g} / \mathrm{dl}$, the RR of ESA doses was 3.1-3.7.

To examine the association of prescribed ESA dose with mortality in HD and PD patients after controlling for potential confounders in the same cohort (fig. 1), we used Cox regression models. Figure la-d shows the death HR across a priori selected ESA dose increments in PD patients. The fully adjusted all-cause death HRs 
Table 3. Unadjusted and adjusted ratio of prescribed dose of ESA in HD patients compared to PD patients across gender and races using multivariate Poisson regression models

\begin{tabular}{lllll}
\hline & Unadjusted & $\begin{array}{l}\text { Hemoglobin- } \\
\text { adjusted }\end{array}$ & $\begin{array}{l}\text { Case-mix- } \\
\text { adjusted }\end{array}$ & $\begin{array}{l}\text { Case-mix-and } \\
\text { MICS-adjusted }\end{array}$ \\
\hline All patients & $3.5(3.4-3.6)$ & $3.4(3.3-3.6)$ & $3.6(3.4-3.7)$ & $3.6(3.5-3.7)$ \\
African-American men & $3.7(3.5-4.0)$ & $3.7(3.5-4.0)$ & $3.8(3.6-4.1)$ & $3.8(3.5-4.1)$ \\
African-American women & $3.7(3.5-4.0)$ & $3.8(3.6-4.0)$ & $4.0(3.7-4.2)$ & $4.0(3.7-4.3)$ \\
Non-African-American men & $3.3(3.1-3.6)$ & $3.3(3.0-3.5)$ & $3.3(3.1-3.6)$ & $3.4(3.2-3.6)$ \\
Non-Africa-American women & $3.4(3.3-3.6)$ & $3.4(3.3-3.5)$ & $3.6(3.4-3.7)$ & $3.7(3.5-3.9)$ \\
\hline
\end{tabular}

ESA doses are averaged over the entire calendar quarter (13 weeks) per patient. Data are from 10,527 PD patients and 139,103 HD patients between 7/2001 and 6/2006.

Table 4. Unadjusted and adjusted ratio of prescribed dose of ESA in HD patients compared to PD patients across hemoglobin levels using multivariate Poisson regression models

\begin{tabular}{lllll}
\hline Hemoglobin & Unadjusted & $\begin{array}{l}\text { Hemoglobin- } \\
\text { adjusted }\end{array}$ & $\begin{array}{l}\text { Case-mix- } \\
\text { adjusted }\end{array}$ & $\begin{array}{l}\text { Case-mix-and } \\
\text { MICS-adjusted }\end{array}$ \\
\hline$<9.0 \mathrm{~g} / \mathrm{dl}$ & $4.1(3.6-4.8)$ & $4.2(3.6-4.8)$ & $4.3(3.7-4.9)$ & $4.4(3.8-5.1)$ \\
9.0 to $<9.5 \mathrm{~g} / \mathrm{dl}$ & $4.6(3.9-5.5)$ & $4.6(3.9-5.5)$ & $4.8(4.0-5.8)$ & $5.0(4.1-6.0)$ \\
9.5 to $<10.0 \mathrm{~g} / \mathrm{dl}$ & $3.1(1.9-4.9)$ & $3.1(1.9-4.9)$ & $3.0(1.9-4.9)$ & $3.1(1.9-4.9)$ \\
10.0 to $<10.5 \mathrm{~g} / \mathrm{dl}$ & $3.8(3.3-4.3)$ & $3.8(3.3-4.3)$ & $3.8(3.3-4.4)$ & $3.8(3.3-4.4)$ \\
10.5 to $<11.0 \mathrm{~g} / \mathrm{dl}$ & $3.8(3.6-4.1)$ & $3.8(3.6-4.2)$ & $4.0(3.7-4.3)$ & $4.0(3.7-4.3)$ \\
11.0 to $<11.5 \mathrm{~g} / \mathrm{dl}$ & $3.6(3.4-3.9)$ & $3.6(3.4-3.9)$ & $3.8(3.5-4.0)$ & $3.7(3.5-4.0)$ \\
11.5 to $<12.0 \mathrm{~g} / \mathrm{dl}$ & $3.2(3.1-3.4)$ & $3.3(3.1-3.5)$ & $3.4(3.2-3.7)$ & $3.4(3.2-3.7)$ \\
12.0 to $<12.5 \mathrm{~g} / \mathrm{dl}$ & $3.5(3.3-3.7)$ & $3.5(3.3-3.7)$ & $3.7(3.5-4.0)$ & $3.7(3.5-3.9)$ \\
12.5 to $<13.0 \mathrm{~g} / \mathrm{dl}$ & $3.6(3.4-3.8)$ & $3.6(3.4-3.8)$ & $3.7(3.5-3.9)$ & $3.7(3.5-4.0)$ \\
13.0 to $<13.5 \mathrm{~g} / \mathrm{dl}$ & $3.4(3.2-3.7)$ & $3.4(3.2-3.7)$ & $3.5(3.3-3.8)$ & $3.5(3.3-3.8)$ \\
13.5 to $<14.0 \mathrm{~g} / \mathrm{dl}$ & $3.4(3.1-3.8)$ & $3.4(3.1-3.8)$ & $3.5(3.1-3.84)$ & $3.5(3.1-3.9)$ \\
$\geq 14 \mathrm{~g} / \mathrm{dl}$ & $3.2(3.0-3.5)$ & $3.2(3.0-3.5)$ & $3.2(3.0-3.4)$ & $3.1(2.9-3.3)$ \\
\end{tabular}

ESA doses are averaged over the entire calendar quarter (13 weeks) per patient. Data are from 10,527 PD patients and 139,103 HD patients between 7/2001 and 6/2006.

for ESA dose increments of 3,000-5,999, 6,000-8,999 and $\geq 9,000 \mathrm{U} /$ week, compared to $<3,000 \mathrm{U} /$ week, were 0.97 (0.87-1.07), 0.85 (0.76-0.95) and 1.08 (0.98-1.18), respectively, indicating no increase in mortality across these ESA increment in PD patients (fig. 1a). We found similar 'flat' trends for cardiovascular death with increasing ESA doses in PD patients (fig. 1b). Indeed, PD patients who received a moderate ESA dose $(6,000$ to $<9,000 \mathrm{U} /$ week) appeared to have the greatest survival. After re-categorizing PD patients with 3 times higher ESA doses (same dosing categories as used for HD patients, see below), extremely high ESA doses were associated with somewhat higher mortality risk (fig. 1). As seen in figure $1 \mathrm{c}, \mathrm{d}$, the fully adjusted all-cause and cardiovascular death HR for ESA dose increments of 10,000$14,999,15,000-19,999$ and $\geq 20,000$ U/week, compared to $<10,000 \mathrm{U} /$ week, were 1.04 (0.94-1.14), 1.30 (1.14-1.47) and 1.28 (1.12-1.47), respectively. We found similar trends in risk of cardiovascular death with very high ESA doses in PD patients. Additional sensitivity analyses confirmed that in PD patients who received ESA $\geq 15,000$ U/week (14\% of all PD population), mortality in the fully adjusted model was $28 \%$ higher than the $86 \%$ of PD patients who received ESA $<15,000 \mathrm{U} /$ week (HR 1.28, 95\% CI 1.16-1.41). Figure 1 also shows death HR for HD patients across 4 a priori selected groups of prescribed 


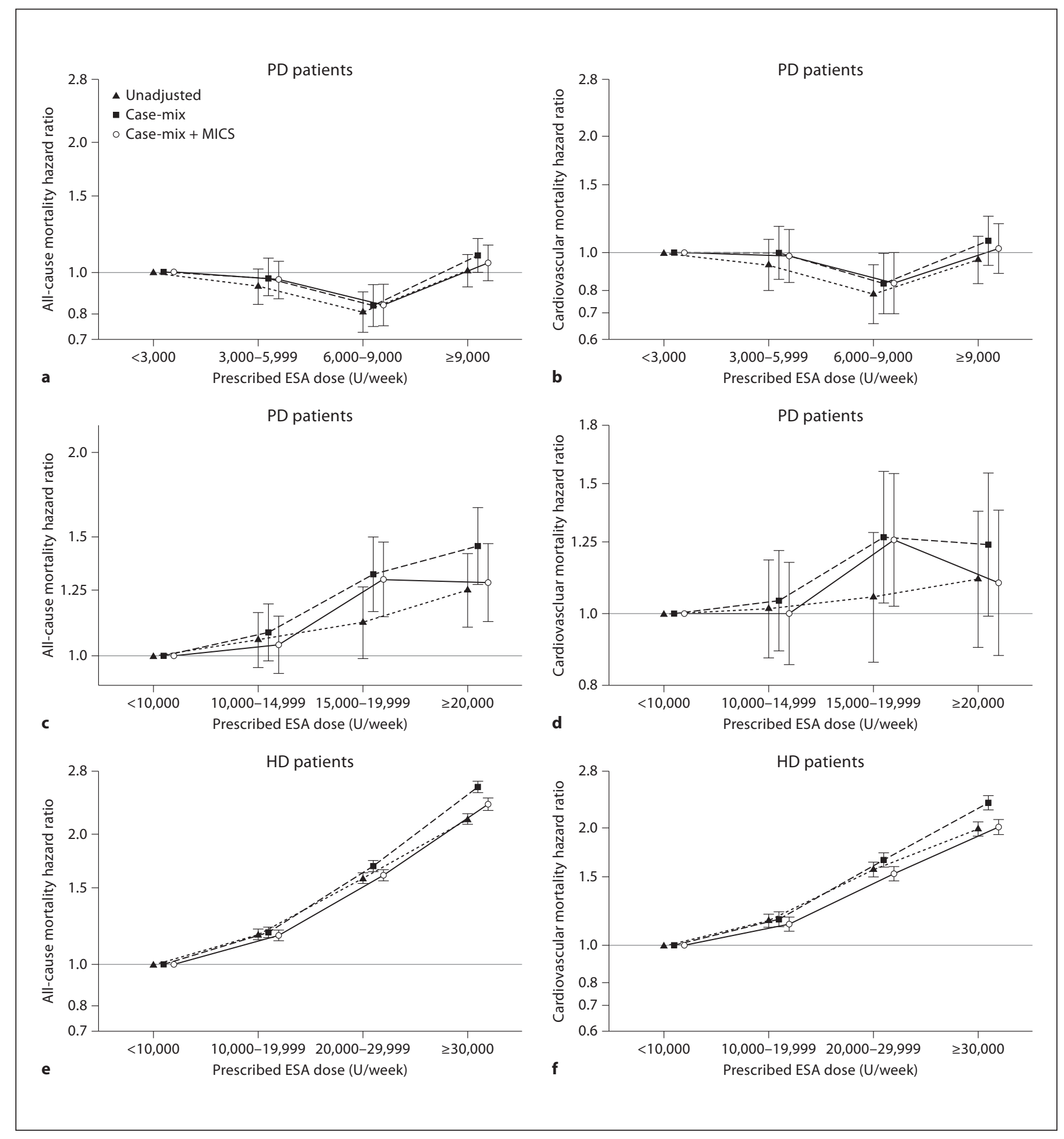

Fig. 1. Hazard ratios of mortality for association of time-averaged weekly ESA dose with all-cause (a, c) and cardiovascular (b, d) mortality in 10,527 PD patients; and all-cause (e) and cardiovascular (f) mortality in 139,103 HD patients. Error bars show $95 \%$ CIs. Case-mix-adjusted models included weekly ESA dose, age, gender, race/ethnicity, ten pre-existing comorbid conditions, history of tobacco smoking, categories of dialysis vintage, primary

insurance, marital status, presence of diabetes, serum ferritin and iron saturation. Case-mix plus malnutrition-inflammation-complex syndrome (MICS)-adjusted models included all of the covariates in the case-mix model as well as body mass index, serum levels of albumin, total iron-binding capacity, creatinine, phosphorus, calcium, bicarbonate, blood white blood cell count and lymphocyte percentage. 


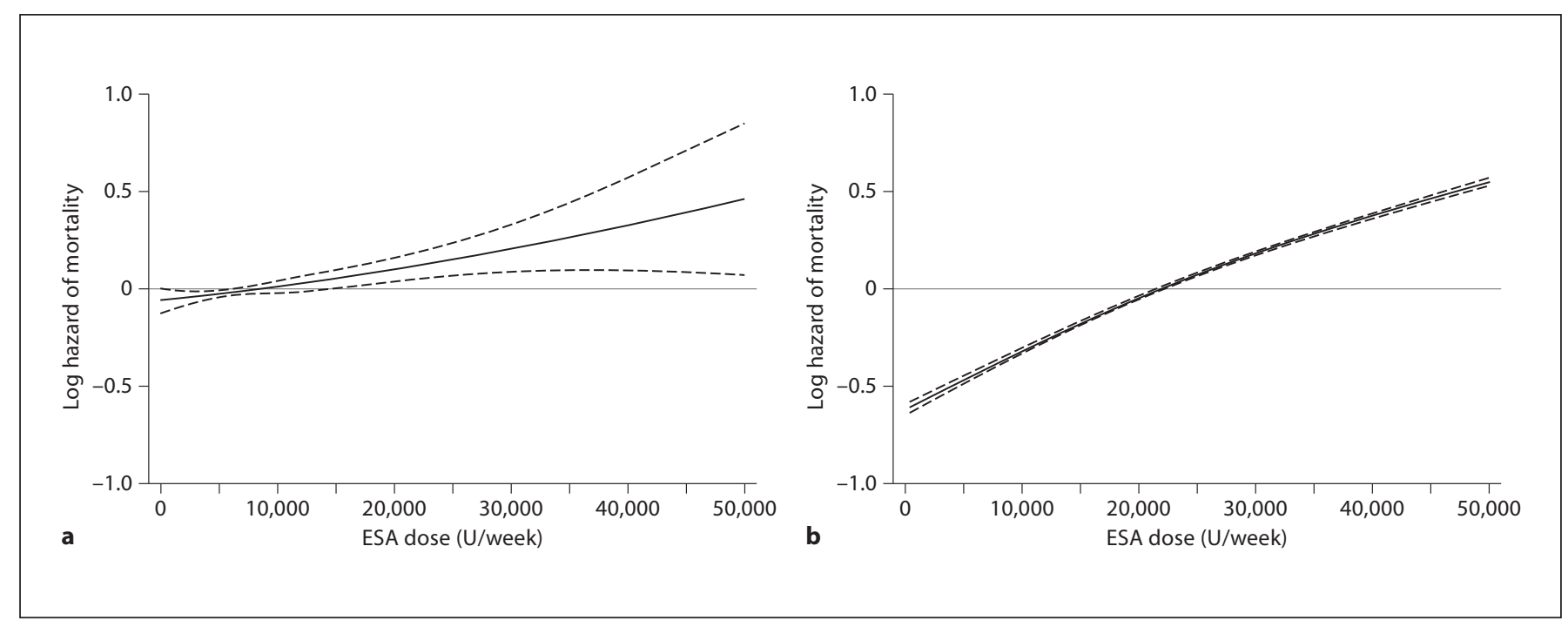

Fig. 2. Multivariate adjusted cubic splines of death hazard ratios and their 95\% confidence levels for all-cause mortality across the entire range of ESA dose in PD (a) and HD (b) patients. Models are adjusted for age, gender, race/ethnicity, ten pre-existing comorbid conditions, history of tobacco smoking, categories of di- alysis vintage, primary insurance, marital status, presence of diabetes, serum ferritin and iron saturation, body mass index, serum levels of albumin, total iron-binding capacity, creatinine, phosphorus, calcium, bicarbonate, blood white blood cell count and lymphocyte percentage.
ESA dose. The fully adjusted all-cause death HR (and 95\% CI) for ESA dose increments of 10,000-19,999, $20,000-29,999$ and $\geq 30,000 \mathrm{U} /$ week, compared to $<10,000 \mathrm{U} /$ week, were 1.14 (1.11-1.17), 1.54 (1.50-1.58) and $2.15(2.10-2.21)$, respectively (fig. 1e). We found similar linear increases in risk of cardiovascular death with increasing ESA doses in HD patients (fig. 1f). Figure 2 shows juxtaposition of the cubic splines of association between ESA dose and mortality in PD and HD patients. In PD patients there was no increase in death up to ESA dose of 15,000 u/week, above which mortality start to rise (fig. 2a), whereas in HD patients any increase in ESA was linearly and incrementally associated with higher death risk (fig. 2b). Online supplementary figure S1 (for all online supplementary material, see www. karger.com/doi/10.1159/000335685) compares adjusted death HRs between HD and PD patients across 20 mutually exclusive subgroups of hemoglobin levels (5 increments) and ESA dose (4 increments). Whereas among HD patients the highest hemoglobin group with the lowest administered ESA had the greatest survival, a different pattern was observed among PD patients. In the latter group, hemoglobin of $11-12 \mathrm{~g} / \mathrm{dl}$ with a moderate ESA dose of 6,000-9,000 U/week appeared associated with the greatest survival and there was no appreciably higher death risk for ESA dose increments.
We also examine the mortality-predictability of ESA responsiveness index, defined as the averaged administered ESA dose divided by hemoglobin in each calendar quarter. As shown in online suppl. table S1, across quartiles of the ESA responsiveness index the mortality risk increased substantially and linearly in HD patients, i.e. 1.2-, 1.6- and 2.4-fold higher death risk in the 2nd to 4th quartiles compared to the 1st quartile. In PD patients, only the highest quartile exhibited a slight increase in death. These associations were confirmed in spline Cox models (online suppl. fig. S2).

\section{Discussion}

In this large and contemporary cohort of 10,527 PD and 139,103 HD patients from one single dialysis provider with relatively uniform anemia management practice patterns between $7 / 2001$ and $6 / 2006$, i.e. during the era with the highest ESA dose administration in the United States, we found that PD patients with the same achieved hemoglobin levels received substantially lower dose of ESA than HD patients, and the difference was even larger among African-Americans. We also found that in PD patients an ESA dose $<10,000 \mathrm{U} /$ week was not associated with higher mortality, but a $28 \%$ higher death risk in 
those receiving significantly higher dose $(>15,000 \mathrm{U} /$ week). In contrast, higher ESA dose was linearly and incrementally associated with higher all-cause and cardiovascular mortality in HD. Similar differences were found in the mortality predictability of ESA responsiveness index between HD and PD patients. Hence, compared to their HD counterparts, PD patients appear to receive lower ESA dosing and were seemingly less amenable to the toxicity and cardiovascular burden associated with higher doses of ESA.

Patients with advanced CKD who undergo PD usually receive lower ESA doses compared to HD modality. Similar results have been reported in the UK Renal Registry by Richardson et al. [20], who reported that the median dose of ESA in PD was 4,000 versus 8,000 U/week in HD patients. These findings were corroborated by Coronel et al. [21] who similarly analyzed data from 132 patients. Several observational studies have shown a slower rate of decline of residual renal function in $\mathrm{PD}$ patients, compared to those treated with HD [37]. It is, thus, possible that the endogenous erythropoietin production in PD patients is higher leading to a lower exogenous ESA requirement for the same achieved hemoglobin level. Whereas in our national administrative database we do have reliable information on residual renal function and its changes over time, we doubt that this per se can account for such a large ESA dose difference between dialysis modalities. The inherent differences in dialysis modality ( 3 times per week exposure to health care providers in HD patients vs. once a month in PD and its effect on patient health) and the frequency and route of ESA administration (intravenous in most HD patients vs. subcutaneous in virtually all PD patients) may contribute to prescribed ESA dose differences. Moreover in HD patients, the frequent phlebotomy for blood testing, the blood loss to the extracorporeal circuit, oozing from vascular access sites post-HD, and vascular access procedures result in iron deficiency and ESA dose difference. Another potential explanation is that HD patients may have a higher prevalence or greater severity of protein-energy wasting as evidenced by higher serum ferritin or C-reactive protein levels [20] and lower BMI and creatinine level (table 1). It is well established that protein-energy wasting contributes to the ESA hypo-responsiveness in CKD patients [23]. In contrast, $\mathrm{PD}$ patients have lower serum albumin levels; this is more likely to be secondary to peritoneal protein losses and not protein-energy wasting [38]. Another important finding was that the HD:PD ratio of ESA dose was even larger in African-Americans, who are known to have greater sur- vival than other racial groups. Whereas racial and ethnic disparities may have a major bearing on CKD patient outcomes, their role in ESA dose difference across modality needs additional studies [39].

In addition to the large discrepancy in ESA requirements by modality, we found that high ESA doses were associated with mortality in HD patients, but in PD patients this association was substantially blunted. Recent reports of prospective randomized trials testing the effect of ESA in patients with CKD including the 'Correction of Hemoglobin and Outcomes in Renal Insufficiency' (CHOIR), 'Cardiovascular Risk Reduction by Early Anemia Treatment with Epoetin Beta' (CREATE) and TREAT studies [7-9] have suggested that using ESA to target normal or near normal hemoglobin level does not confer a survival benefit. Concern has been raised about these treatment strategies as there may potentially be a causal association between higher ESA use and increased risk of serious cardiovascular and thromboembolic events such as hypertension [40] and stroke in CKD [7, 41], and in cancer patients [42]. Whereas it has been suggested that the ESA hyporesponsiveness is a true confounder for the association between hemoglobin and mortality in randomized trials and that the variable ESA requirements may generate confounding by indication [16], it is possible that ESA activates or increases the number of platelets, probably via both relative iron depletion and its inherent pro-poikilosis effect, leading to a higher risk of thromboembolic events [18]. To this end, any renal replacement therapy modality that can lower ESA requirement is potentially more favorable. This, of course, comes with the added advantage of potential cost-savings.

Whereas the association of ESA dose with mortality was linear across all dose ranges in $\mathrm{HD}$ patients, in $\mathrm{PD}$ patients, only doses higher than 15,000 U/week were associated with slightly higher mortality risk. Interestingly, the usual doses of ESA used in everyday clinical practice for the care of each dialysis modality was not associated with higher mortality in PD, but it was associated with excess death risk in HD patients. In our study we found that there was some increased risk when the ESA doses exceeded 15,000 U/week in PD patients but in HD patients, the dose-mortality association was linear, robust and incremental. Further comparative effectiveness studies and controlled trials are needed to examine these questions [19].

There are additional and potentially plausible explanations of the association between higher ESA dose and mortality. Patients with higher ESA requirements may be 
at higher risk for adverse outcomes due to the underlying reasons for their ESA hyporesponsiveness such as protein-energy wasting, inflammation [23], comorbidities [43] and additional yet-unmeasured factors due to potential 'off-target', nonerythropoietic effects of the higher administered ESA doses or conditions precipitated by the higher doses of ESA such as iron depletion and platelet activation $[18,44]$, or due to a combination of these. A recent secondary analysis of the TREAT showed that a poor initial response to ESA therapy was associated with increased cardiovascular and all-cause mortality [15]. Indeed, a re-analysis of the CHOIR trial led to a similar conclusion that the severity of comorbidities may have confounded the associations between ESA use and outcomes [6].

Our study is notable for its large sample size and capturing the anemia management practice pattern during a contemporary period of time (2001-2006) where ESA administration to US dialysis patients was at an all-time high [11]. The detailed and rich information on clinical and laboratory data allowed us to control for an extensive range of confounders related to the mortality of $\mathrm{PD}$ or HD patients. There are also certain limitations of our study that need to be emphasized. Observational studies, such as ours, cannot examine the causality. The information on comorbidities in our study was limited to that obtained from Medical Evidence Form 2728, a form in which comorbid conditions are significantly underreported [45]. Only baseline comorbidities were included in the statistical models and it is quite conceivable that patients can develop additional illnesses over time that were not accounted for in the analyses. Another potential limitation is the lack of explicit laboratory markers of inflammation such as C-reactive protein. However, we used such data as serum albumin, total iron-binding capacity, blood white blood cell count and lymphocyte percentage, which have significant associations with inflammation and malnutrition in dialysis patients [30]. Similarly to other observational studies, unmeasured confounding was not addressed. Finally, data on access thrombosis and stroke were not available and were not studied herein.

\section{Conclusions}

In a large and contemporary cohort of over 100,000 $\mathrm{HD}$ and PD patients in the United States between 2001 and 2006, we found that PD patients with the same level of hemoglobin received a substantially lower dose of
ESA than HD patients. Racial disparities in ESA dose ratio between $\mathrm{HD}$ and $\mathrm{PD}$ were observed. Increasing ESA dose and higher ESA responsiveness index were associated with higher mortality risk in HD patients. However, the associations of ESA dose or responsiveness with death were substantially mitigated in PD patients, where doses significantly higher than used in clinical practice or the highest ESA responsiveness index were associated with only slight increase in mortality risk. Additional comparative effectiveness studies and prospective controlled trials are needed to obtain the target hemoglobin level and the effect of anemia therapy as a function of ESA responsiveness in PD and HD patients.

\section{Acknowledgements}

We thank DaVita Clinical Research (DCR) for providing the clinical data, analysis and review for this research project.

The study was supported by research grants from the National Institute of Diabetes, Digestive and Kidney Disease of the National Institutes of Health R21 DK 077341 (K.K.-Z. and R.M.), a philanthropist grant from Mr. Harold Simmons (K.K.Z.), and research grants from DaVita Clinical Research (K.K.-Z. and R.M.). M.Z.M. received grants from the National Developmental Agency (KTIA-OTKA-EU 7KP-HUMAN-MB08-A-81231) from the Research and Technological Innovation Fund, was also supported by Hungarian Kidney Foundation.

\section{Disclosure Statement}

Rajnish Mehrotra has received grant support from Amgen and Baxter Healthcare and honoraria from Baxter Healthcare.

References

Duong/Kalantar-Zadeh/Molnar/ Zaritsky/Teitelbaum/Kovesdy/Mehrotra 
4 Molnar MZ, Czira M, Ambrus C, Szeifert L, Szentkiralyi A, Beko G, Rosivall L, Remport A, Novak M, Mucsi I: Anemia is associated with mortality in kidney-transplanted patients - a prospective cohort study. Am J Transplant 2007;7:818-824.

5 Kalantar-Zadeh K, Aronoff GR: Hemoglobin variability in anemia of chronic kidney disease. J Am Soc Nephrol 2009;20:479-487.

-6 Szczech LA, Barnhart HX, Sapp S, Felker GM, Hernandez A, Reddan D, Califf RM, Inrig JK, Patel UD, Singh AK: A secondary analysis of the CHOIR trial shows that comorbid conditions differentially affect outcomes during anemia treatment. Kidney Int 2010;77:239-246.

7 Singh AK, Szczech L, Tang KL, Barnhart H, Sapp S, Wolfson M, Reddan D: Correction of anemia with epoetin alfa in chronic kidney disease. N Engl J Med 2006;355:2085-2098.

$\checkmark 8$ Drueke TB, Locatelli F, Clyne N, Eckardt KU, Macdougall IC, Tsakiris D, Burger HU, Scherhag A: Normalization of hemoglobin level in patients with chronic kidney disease and anemia. N Engl J Med 2006;355:2071-2084.

-9 Pfeffer MA, Burdmann EA, Chen CY, Cooper ME, de Zeeuw D, Eckardt KU, Feyzi JM, Ivanovich $\mathrm{P}$, Kewalramani R, Levey AS, Lewis EF, McGill JB, McMurray JJ, Parfrey P, Parving HH, Remuzzi G, Singh AK, Solomon SD, Toto R: A trial of darbepoetin alfa in type 2 diabetes and chronic kidney disease. N Engl J Med 2009;361:2019-2032.

-10 Szczech LA, Barnhart HX, Inrig JK, Reddan DN, Sapp S, Califf RM, Patel UD, Singh AK: Secondary analysis of the CHOIR trial epoetin-alpha dose and achieved hemoglobin outcomes. Kidney Int 2008;74:791-798.

11 Thamer M, Zhang Y, Kaufman J, Cotter D, Dong F, Hernan MA: Dialysis facility ownership and epoetin dosing in patients receiving hemodialysis. JAMA 2007;297:1667-1674.

12 Coyne DW: Use of epoetin in chronic renal failure. JAMA 2007;297:1713-1716.

13 Kaysen GA, Muller HG, Ding J, Chertow GM: Challenging the validity of the EPO index. Am J Kidney Dis 2006;47:166.

-14 Zhang Y, Thamer M, Stefanik K, Kaufman J, Cotter DJ: Epoetin requirements predict mortality in hemodialysis patients. Am J Kidney Dis 2004;44:866-876.

- 15 Solomon SD, Uno H, Lewis EF, Eckardt KU, Lin J, Burdmann EA, de Zeeuw D, Ivanovich P, Levey AS, Parfrey P, Remuzzi G, Singh AK, Toto R, Huang F, Rossert J, McMurray JJ, Pfeffer MA: Erythropoietic response and outcomes in kidney disease and type 2 diabetes. N Engl J Med 2010;363:1146-1155.

-16 Bradbury BD, Brookhart MA, Winkelmayer WC, Critchlow CW, Kilpatrick RD, Joffe MM, Feldman HI, Acquavella JF, Wang O, Rothman KJ: Evolving statistical methods to facilitate evaluation of the causal association between erythropoiesis-stimulating agent dose and mortality in nonexperimental research: strengths and limitations. Am J Kidney Dis 2009;54:554-560.
17 Bradbury BD, Danese MD, Gleeson M, Critchlow CW: Effect of Epoetin alfa dose changes on hemoglobin and mortality in hemodialysis patients with hemoglobin levels persistently below $11 \mathrm{~g} / \mathrm{dl}$. Clin J Am Soc Nephrol 2009;4:630-637.

18 Streja E, Kovesdy CP, Greenland S, Kopple JD, McAllister CJ, Nissenson AR, KalantarZadeh K: Erythropoietin, iron depletion, and relative thrombocytosis: a possible explanation for hemoglobin-survival paradox in hemodialysis. Am J Kidney Dis 2008;52: 727-736.

19 Strippoli GF: Effects of the dose of erythropoiesis stimulating agents on cardiovascular events, quality of life, and health-related costs in hemodialysis patients: the clinical evaluation of the dose of erythropoietins (C.E. DOSE) trial protocol. Trials 2010;11:70.

20 Richardson D, Ford D, Gilg J, Williams AJ: UK Renal Registry 11th Annual Report (December 2008). Chapter 9: Haemoglobin, ferritin and erythropoietin amongst patients receiving dialysis in the UK in 2007: national and centre-specific analyses. Nephron Clin Pract 2009;111(suppl 1):c149-c183.

21 Coronel F, Herrero JA, Montenegro J, Fernandez C, Gandara A, Conesa J, Rivera MT, Torrente J, Portoles J, Gomez-Martino JR: Erythropoietin requirements: a comparative multicenter study between peritoneal dialysis and hemodialysis. J Nephrol 2003;16:697702.

22 Kalantar-Zadeh K, Lee GH, Miller JE, Streja E, Jing J, Robertson JA, Kovesdy CP: Predictors of hyporesponsiveness to erythropoiesis-stimulating agents in hemodialysis patients. Am J Kidney Dis 2009;53:823-834.

23 Kalantar-Zadeh K, McAllister CJ, Lehn RS, Lee GH, Nissenson AR, Kopple JD: Effect of malnutrition-inflammation complex syndrome on EPO hyporesponsiveness in maintenance hemodialysis patients. Am J Kidney Dis 2003;42:761-773.

24 Wei M, Bargman JM, Oreopoulos DG: Factors related to erythropoietin hypo-responsiveness in patients on chronic peritoneal dialysis. Int Urol Nephrol 2007;39:935-940.

25 Finkelstein FO, Juergensen P, Wang S, Santacroce S, Levine M, Kotanko P, Levin NW, Handelman GJ: Hemoglobin and plasma vitamin C levels in patients on peritoneal dialysis. Perit Dial Int 2011;31:74-79.

26 Axelsson J, Qureshi AR, Heimburger O, Lindholm B, Stenvinkel P, Barany P: Body fat mass and serum leptin levels influence epoetin sensitivity in patients with ESRD. Am J Kidney Dis 2005;46:628-634.

27 Raja R, Bloom E, Johnson R, Goldstein M: Improved response to erythropoietin in peritoneal dialysis patients as compared to hemodialysis patients: role of iron deficiency. Adv Perit Dial 1994;10:135-138.
28 Streja E, Kovesdy CP, Molnar MZ, Norris KC, Greenland S, Nissenson AR, Kopple JD, Kalantar-Zadeh K: Role of nutritional status and inflammation in higher survival of African American and Hispanic hemodialysis patients. Am J Kidney Dis 2011;57:883-893.

29 Molnar MZ, Mehrotra R, Duong U, Bunnapradist S, Lukowsky LR, Krishnan M, Kovesdy CP, Kalantar-Zadeh K: Dialysis modality and outcomes in kidney, transplant recipients. Clin J Am Soc Nephrol 2011, Epub ahead of print

-30 Molnar MZ, Huang E, Hoshino J, Krishnan M, Nissenson AR, Kovesdy CP, KalantarZadeh K: Association of pretransplant glycemic control with posttransplant outcomes in diabetic kidney transplant recipients. Diabetes Care 2011;34:2536-2541.

- 31 Molnar MZ, Lukowsky LR, Streja E, Dukkipati R, Jing J, Nissenson AR, Kovesdy CP, Kalantar-Zadeh K: Blood pressure and survival in long-term hemodialysis patients with and without polycystic kidney disease. J Hypertens 2010;28:2475-2484.

-32 Sampaio MS, Molnar MZ, Kovesdy CP, Mehrotra R, Mucsi I, Sim JJ, Krishnan M, Nissenson AR, Kalantar-Zadeh K: Association of pretransplant serum phosphorus with posttransplant outcomes. Clin J Am Soc Nephrol 2011;6:2712-2721.

33 Miller JE, Kovesdy CP, Norris KC, Mehrotra R, Nissenson AR, Kopple JD, Kalantar-Zadeh K: Association of cumulatively low or high serum calcium levels with mortality in long-term hemodialysis patients. Am J Nephrol 2010;32:403-413.

- 34 Molnar MZ, Kovesdy CP, Musci I, Bunnapradist S, Streja E, Krishnan M, KalantarZadeh K: Higher recipient body mass index is associated with post-transplant delayed kidney graft function. Kidney Int 2011;80:218-224.

- 35 Duong U, Mehrotra R, Molnar MZ, Noori N, Kovesdy CP, Nissenson AR, Kalantar-Zadeh $\mathrm{K}$ : Glycemic control and survival in peritoneal dialysis patients with diabetes mellitus. Clin J Am Soc Nephrol 2011;6:1041-1048.

-36 Longenecker JC, Coresh J, Klag MJ, Levey AS, Martin AA, Fink NE, Powe NR: Validation of comorbid conditions on the end-stage renal disease medical evidence report: the CHOICE study. Choices for healthy outcomes in caring for ESRD. J Am Soc Nephrol 2000;11:520-529.

37 Misra M, Vonesh E, Van Stone JC, Moore HL, Prowant B, Nolph KD: Effect of cause and time of dropout on the residual GFR: a comparative analysis of the decline of GFR on dialysis. Kidney Int 2001;59:754-763.

38 Mehrotra R, Duong U, Jiwakanon S, Kovesdy CP, Moran J, Kopple JD, Kalantar-Zadeh $\mathrm{K}$ : Serum albumin as a predictor of mortality in peritoneal dialysis: comparisons with hemodialysis. Am J Kidney Dis 2011;58: 418-428. 
-39 Kalantar-Zadeh K, Golan E, Shohat T, Streja E, Norris KC, Kopple JD: Survival disparities within American and Israeli dialysis populations: learning from similarities and distinctions across race and ethnicity. Semin Dial 2010;23:586-594.

40 Vaziri ND: Role of oxidative stress in the pathogenesis of erythropoietin-induced hypertension. Am J Hypertens 2010;23:226227.

-41 Heinze G, Kainz A, Horl WH, Oberbauer R: Mortality in renal transplant recipients given erythropoietins to increase haemoglobin concentration: cohort study. BMJ 2009; 339:b4018.
42 Bennett CL, Silver SM, Djulbegovic B, Samaras AT, Blau CA, Gleason KJ, Barnato SE, Elverman KM, Courtney DM, McKoy JM, Edwards BJ, Tigue CC, Raisch DW, Yarnold PR, Dorr DA, Kuzel TM, Tallman MS, Trifilio SM, West DP, Lai SY, Henke M: Venous thromboembolism and mortality associated with recombinant erythropoietin and darbepoetin administration for the treatment of cancer-associated anemia. JAMA 2008;299: 914-924.
43 Lopez-Gomez JM, Portoles JM, Aljama P: Factors that condition the response to erythropoietin in patients on hemodialysis and their relation to mortality. Kidney Int 2008:S75-S81.

44 Kalantar-Zadeh K, Streja E, Miller JE, Nissenson AR: Intravenous iron versus erythropoiesis-stimulating agents: friends or foes in treating chronic kidney disease anemia? Adv Chronic Kidney Dis 2009;16:143-151.

45 Schwedler SB, Coresh J, Schinzel R: Advanced glycation end products and mortality in caring for ESRD. Kidney Int 2000;11:520529.

\section{Erratum}

In reference to the manuscript entitled 'Metabolic Syndrome, Components, and Cardiovascular Disease Prevalence in Chronic Kidney Disease: Findings from the Chronic Renal Insufficiency Cohort (CRIC) Study' by Townsend et al. [Am J Nephrol 2011;33:477484], the following grant acknowledgments were inadvertently omitted by the authors: (a) University of Pennsylvania Scientific \& Data Coordinating Center U01DK060990; (b) The Johns Hopkins University UL1 RR-025005; (c) University of Maryland GCRC M01 RR-16500; (d) Case Western Reserve University Clinical and Translational Science Collaborative (University Hospitals of Cleveland, Cleveland Clinic Foundation, and MetroHealth) UL1 RR-024989; (e) University of Michigan M01 RR-000042 and UL1 RR024986; (f) University of Illinois at Chicago CTSA UL1RR029879; (g) Tulane/LSU/Charity Hospital General Clinical Research Center RR-05096, and (h) Kaiser NIH/NCRR UCSF-CTSI UL1 RR-024131. 